\title{
Episodic, Event-triggered Staring Compulsion: An Unusual Form of Obsessive-compulsive Disorder
}

\author{
Harish Kulkarni
}

\begin{abstract}
Obsessive-compulsive disorder (OCD) has varied presentations. An OCD with predominant mental compulsion is rare. A case presented here is of a 21-year-old male patient with staring episodes. He got the urge to stare at uninteresting and insignificant visual cues while reading. Symptoms appeared only while reading academic books and during his examinations. Symptoms caused him significant distress and dysfunction; hence, he was unable to read for the examinations. His unsuccessful attempts to overcome the act of staring made him more anxious. Other differential diagnoses like impulse control disorder, attention deficit hyperactivity disorder, mania, and generalized anxiety disorder were ruled out and diagnosis of OCD was made. The patient was treated with selective serotonin reuptake inhibitors: paroxetine $25 \mathrm{mg}$ and later fluoxetine up to $60 \mathrm{mg}$ with propranolol and clonazepam initially. Significant improvement was noted on follow-ups, which maintained even after medications were withdrawn. Keywords: Compulsive behavior, Obsessive-compulsive disorder, Reading, Young adult. Indian Journal of Private Psychiatry (2020): 10.5005/jp-journals-10067-0053
\end{abstract}

\section{INTRODUCTION}

Obsessive-compulsive disorder (OCD) is a common psychiatric disorder but with myriad presentations. Of all, predominant compulsion type of OCD is relatively uncommon accounting for a mere $2 \%$ of cases and OCD with predominant/pure mental compulsion hardly constitutes for $0.2 \%$. ${ }^{1}$ Staring, a form of mental ritual, is seen with other compulsive behavior but very rarely in isolation. A rare form of presentation of OCD is being reported for its uniqueness in symptomatology, onset, and course. The diagnostic challenge it posed is also discussed.

\section{Case Description}

A 21-year-old male medical student premorbid well adjusted with uneventful childhood and no family history of psychiatric illness or substance use reported to outpatient department of psychiatry with inability to concentrate on studying, despite his best efforts. He got repeatedly distracted from studying, by minor stimuli like a dot, a speck, a mark, a line on his palm, spectacles, or pages anywhere in his field of vision while he prepared for his upcoming examination. He felt a strong urge to stare at them and attempted to resist it and resumed studying made him anxious with associated palpitations, restlessness, and sweating. He was compelled to shift his attention from studying to keep staring at these visual cues for some time or until he felt satisfied. He could switch back to studying for a short period of time only to be distracted again. Stimuli were meaningless to him and felt that the irrepressible urge to look at them was totally irrational. Occasionally, he doubted that not staring at them would result in missing something important despite being aware of its insignificance. The urge to stare was usually not preceded by any thoughts. Staring at those stimuli reduced his anxiety momentarily. He tried various ways to overcome staring episodes; he created other marks on the page and hands intentionally so that no particular mark distracted him; he kept marks close to the line and he was reading to avoid looking away. All the attempts failed to prevent the staring episodes. With repeated failed attempts to focus, he quit reading as it was unbearable for him to continue. He spent a significant amount of his valuable time
Department of Psychiatry, SN Medical College, Bagalkot, Karnataka, India

Corresponding Author: Harish Kulkarni, Department of Psychiatry, SN Medical College, Bagalkot, Karnataka, India, Phone:+919538933846, e-mail: harishkulkarni14@gmail.com

How to cite this article: Kulkarni H. Episodic, Event-triggered Staring Compulsion: An Unusual Form of Obsessive-compulsive Disorder. Ind J Priv Psychiatry 2020;14(1):9-10.

Source of support: Nil

Conflict of interest: None

in these activities that slowed down the pace of studying and was unable to complete his syllabus that made him more anxious. He took up smoking nicotine to reduce his anxiety but without much benefit. The symptom appeared only when studying irrespective of the topic or subject. Nonacademic reading like text messages or newspaper was not hampered. The patient was in a dilemma whether to study with great difficulty or not take the examination. This resulted in skipping the examination in the past. He did not report other obsessions or compulsions. There were no features of attention deficit hyperactivity disorder, mania, depression, or psychosis. The patient had similar symptoms twice in the past during previous examinations. The patient had no symptoms in the interval period. On earlier psychiatric consultations, he had received diagnoses like generalized anxiety disorder, adjustment disorder with anxiety features. He was treated with beta-blocker, benzodiazepines, and SNRIs (desvenlafaxine $100 \mathrm{mg}$ ) without much relief. On examination, there was tachycardia, sweating, and mild elevation in blood pressure. He was anxious, hesitant, and stuttered often, and had numerous pen marks on his hands; cognitive functions were normal, and social judgment was impaired and had good insight into the symptoms. The diagnosis of OCD with predominantly compulsive acts was made using ICD-10 criteria as the presence of compulsion alone was enough for the diagnosis as per diagnostic guidelines. Administration of Yale Brown obsessivecompulsive scale (YBOCS) symptom checklist did not reveal other obsessions or compulsions. Baseline score on YBOCS rating scale 
was 17 of 20 since only compulsions were rated, indicating extreme severity. The patient was treated with daily dosage of paroxetine $25 \mathrm{mg}$, clonazepam $0.5 \mathrm{mg}$, and propranolol of $20 \mathrm{mg}$ tablets. At two weeks of follow-up, YBOCS score reduced to 11. He was asymptomatic at eight weeks of follow-up. He appeared for his upcoming examination that year and cleared it. Later on, treatment was changed to fluoxetine capsule and maintained on $60 \mathrm{mg}$ as he felt sedated with earlier medications. During his subsequent examinations, he developed no symptoms. At the end of two years of treatment, he scored zero on YBOCS. Medications were tapered off and stopped. He was maintaining well even after one year of stopping treatment.

\section{Discussion}

Predominant compulsions are rare than predominant obsessions. Mental compulsions in the absence of obsessions are extremely rare. The patient had compulsion in the absence of a clear obsession. Urge, in this case, can be arguably considered as a part of compulsion. Obsessive urges are usually described in obsessional phobia; these urges are to carry out a dreaded act and the subsequently arising avoidance of the object/situation is a controlling compulsion. Unlike obsessional phobia, here the act of staring was a yielding compulsion. Furthermore, the compulsions are considered to have urges as intrinsic component that drives the act. This urge follows an obsessive thought but precedes the compulsive act. Thus, compulsion is a combination of an urge and a behavior. ${ }^{2}$ Hence, here the presence of urges was considered as a part of compulsion instead of an obsession.

Staring as mental ritual has been described as compulsive behavior in children with $O C D^{3}$ and is associated with other obsessions and compulsions. Staring as a mental ritual is rare as compared to other mental rituals like counting and rehearsing and the presence of staring alone has not been reported hitherto. ${ }^{4}$ Compulsive staring is described as a type of mental checking behavior and following an obsessive doubt. Mental checking is reevaluation of past events or information obtained ${ }^{5}$ as they are plagued by the doubt. ${ }^{1}$ The patient did not report pervasive pathological doubt and reevaluation and he used to stare as long as it felt "just right."

In OCD, symptoms that are not present otherwise can be brought in by triggers like in obsessional phobias. Triggers in OCD are defined as an event or an external or internal cue that sets off an obsession/compulsion. ${ }^{2}$ Trigger in this case was reading and the urge was to stare at something totally different. The urge was not related to trigger and was directed at silly visual cues; also, the trigger was highly specific, i.e., reading textbooks only. Urges in OCD differ from impulse-control-disorder; in former, impulses/urges are repetitive, controllable to an extent, can be postponed, lengthened/ abbreviated, or concealed and distressing even in absence of urges, thus differentiating it from latter. ${ }^{2}$

Many psychiatric illnesses have onset with stress ${ }^{6}$ but only few illnesses like adjustment disorder subside with the removal of stressor alone. Peculiar in this case was occurrence of illness, which was well predicted by the arrival of examinations and remitted after that without treatment. Such a presentation of OCD is unusual though episodic OCD has been reported. ${ }^{7}$

Diagnosis of this case posed a challenge owing to its atypical presentation. The diagnosis needed repeated interviews.
Self-awareness of the staring episodes, ability to terminate ongoing act differentiated it from seizure. Oculogyric crisis was ruled out as the staring acts were painless, brought about by specific stimuli and the patient modulated the act. In the present case, the presence of repetitive, irrational, intrusive, irresistible behavior, tension building up to be relieved only after the act, distress, and impairment in his daily routine clinched the diagnosis allaying the doubts.

\section{Conclusion}

In conclusion, here is a case of OCD with unusual presentation of mental compulsion of staring and no obsession or other compulsion, symptoms were triggered by reading, and illness had well-defined episodic course. The patient improved with pharmacotherapy and persisted in remission even off treatment. The challenge posed by the illness to diagnose reminds us that illness presents in many possible ways: from the complex interplay of symptoms to a single subclinical complaint. Atypical presentations are rather a rule than exception but for a patient, it is just suffering. For an apt diagnosis and treatment, the clinician's skill and knowledge come to aid; hence, the need is to discuss rare and unusual presentations.

\section{Clinical Significance}

Pure mental compulsions in the absence of obsession or other compulsions are rare. Staring spells as a mental compulsion is presented here which was event triggered, event being reading textbooks, and episodic in nature, appeared usually prior to examinations. The unusual presentations are challenge for practitioners to diagnose. Although the presentation was confusing, symptom improvement with standard treatment was classic.

\section{Declaration of Patient Consent}

The patient consent statement was taken for participation in the study and publication of the clinical information without revealing his identity, name, or initials. The patient is aware that although confidentiality would be maintained, anonymity cannot be guaranteed.

\section{References}

1. Pato MT, Fanous A, Eise $J$, et al. Anxiety disorders: obsessivecompulsive disorder. In: Kay J, Tasman A, Lieberman JA, et al. Psychiatry. New Jersey: John Wiley \& Sons Ltd.; 2008; 3. pp. 1443-1467.

2. Rachman S, De Silva P. The Facts: Obsessive-compulsive Disorder, 4th ed., Oxford: Oxford university press; 2009.

3. James S, Farell L, Zimmer-Gembeck M. Description and prevalence of OCD in children and adolescents. In: Abromowitz J, McKay D, Storch E. The Wiley Handbook of Obsessive Compulsive Disorder. New Jersey: John Wiley \& sons Ltd.; 2017. pp. 5-18. DOI: 10.1002/9781118890233.ch1

4. Gillihan, SJ, Williams MT, Malcoun M, et al.Common pitfalls in exposure and response prevention (EX/RP) for OCD. J Obsessive Compuls Relat Disord 2012;1(4):251-257. DOI: 10.1016/j.jocrd.2012.05.002.

5. Seay SJ. OCD \& Checking: Part 2 (Mental Checking). Accessed on 27/07/2020. http://www.steveseay.com/mental-checking-ocd/.

6. Zohar J, Fostick L, Wetzler EJ. Obsessive compulsive disorder. In: Gelder M, Andreasen N, Lopez-lbor J Jr, et al. New Oxford textbook of Psychiatry, 2nd ed., Oxford: Oxford University Press; 2009. pp. 765-773. DOI: 10.1093/med/9780199696758.003.0100.

7. Sidana A, Singhal R, Sharma RP. Episodic obsessive compulsive disorder: a case report. Indian J Psychiatry 2002;44(3):303-304. 